\title{
Feasibility study of the geoelectric structure of the Araguainha impact, Brazil
}

\author{
Pierre-André Schnegg ${ }^{1}$ and S. L. Fontes ${ }^{2}$ \\ ${ }^{1}$ Institut de Géologie, CH-2007 Neuchâtel, Switzerland \\ ${ }^{2}$ CNPq-Observatorio Nacional, 20921-400 Rio de Janeiro, Brazil
}

(Received December 7, 2000; Revised October 4, 2001; Accepted October 4, 2001)

\begin{abstract}
We have re-examined the modelling of magnetotelluric and GDS soundings carried out on the Araguainha Dome, Brazil, published a few years ago, in the light of a new modelling method and with particular stress on the induction of the vertical component of the magnetic field, which had been neglected in the early publications. By careful selection of the period range of the measured data, we obtain a set of radially symmetric induction arrows. This symmetry is taken as a first order assumption of the modelling scheme. The result is an improvement of the resolution of the radial distribution of depths to the crater basement. Due to the poor MT site coverage of the crater area, this work must be considered a feasibility study rather than a final modelling contribution.
\end{abstract}

\section{Introduction}

It is not uncommon to see tensorial magnetotelluric (MT) data being modelled by using only one polarisation (TE or TM mode). Sometimes, no check is even done to verify the validity of the final model with regard to the other polarisation. Similarly, the vertical component of the magnetic field is often neglected in modelling the MT data. This is a pity, since every independent parameter can potentially contribute to enhance the true characteristics of the model while simultaneously suppressing artefacts. There is generally no technical limitation to include the vertical field in the modelling, since today the major forward modelling methods provide access to this component of the magnetic field.

A few years ago, we published the results of a MT investigation of the Araguainha impact crater, located in Central Brazil (Fig. 1) (Masero et al., 1994, 1997). The first paper dealt only with 1D modelling using the short-period part of the data, and did not mention the vertical magnetic field. The second paper attempted 2D and 3D modelling of the impact structure and mentioned the radial symmetry displayed by the induction arrows around the uplifted basement core of the crater, but did not include the constraint imposed on the modelling by the vertical field. In the present article, we take advantage of our recent 3D modelling scheme (Schnegg, 1999) to improve our model of the crater internal structure, taking the vertical magnetic field into account. We believe that this inclusion can be extremely beneficial, since this component of the field is at the same time 1) highly sensitive to lateral conductivity variations, and 2) free of static shift errors. In contrast, even tensorial MT information appears quite structureless in the period range of interest. Furthermore, this data is known for being highly static shiftprone. Although this effect seems to be of limited extent here, we will see that it masks small details such as the ring

Copy right (C) The Society of Geomagnetism and Earth, Planetary and Space Sciences (SGEPSS); The Seismological Society of Japan; The Volcanological Society of Japan; The Geodetic Society of Japan; The Japanese Society for Planetary Sciences. structure of the basement.

\section{Geological Setting}

The Araguainha Dome is the largest known impact structure in South America with a diameter of $40 \mathrm{~km}$. It lies within the sediments of the intracratonic Paraná basin over Phanerozoic sedimentary rocks. A simplified geological map of the Araguainha Dome is given in Fig. 1.

The northern section of the basin, in which the crater is located, is marked by metasediments of the Paraguay Geosynclinal (Cordani et al., 1984) interrupted by a series of large faults. The continuation of these faults within the Paraná basin represents a significant NE-SW trending tectonic lineament of the basement underneath the Araguainha Dome associated to the Transbrazilian Lineament which is considered a tectonic feature of continental extension.

The cosmic origin of the Dome was found by the analysis of samples from the uplifted basement (Dietz and French, 1973; Crósta et al., 1981), showing clearly the occurrence of shock metamorphism (shatter cones, crystalline to amorphous state transformations). Isotopic investigations (Engelhardt et al., 1992) revealed an impact age close to the Permian-Triassic boundary. The shape of the Dome is typical of a complex crater, with an uplifted basement core of $10 \mathrm{~km}$ diameter at the centre of a system of small concentric hills, ridges, faults and valleys.

An aeromagnetic survey of the Precambrian basement in the areas surrounding the Dome (Theilen-Willige, 1982) determined a sediment thickness of $2000 \mathrm{~m}$. A borehole drilled $50 \mathrm{~km}$ WSW for oil exploration met the basement at a depth of $1947 \mathrm{~m}$. Simple 1D modelling of our MT data showed a depth to the basement of $1500 \mathrm{~m}$ (Masero et al., 1994), but careful 2D modelling of the same data showed that the fractured zone segment extended down to 3-7 km (Masero et al., 1997). 


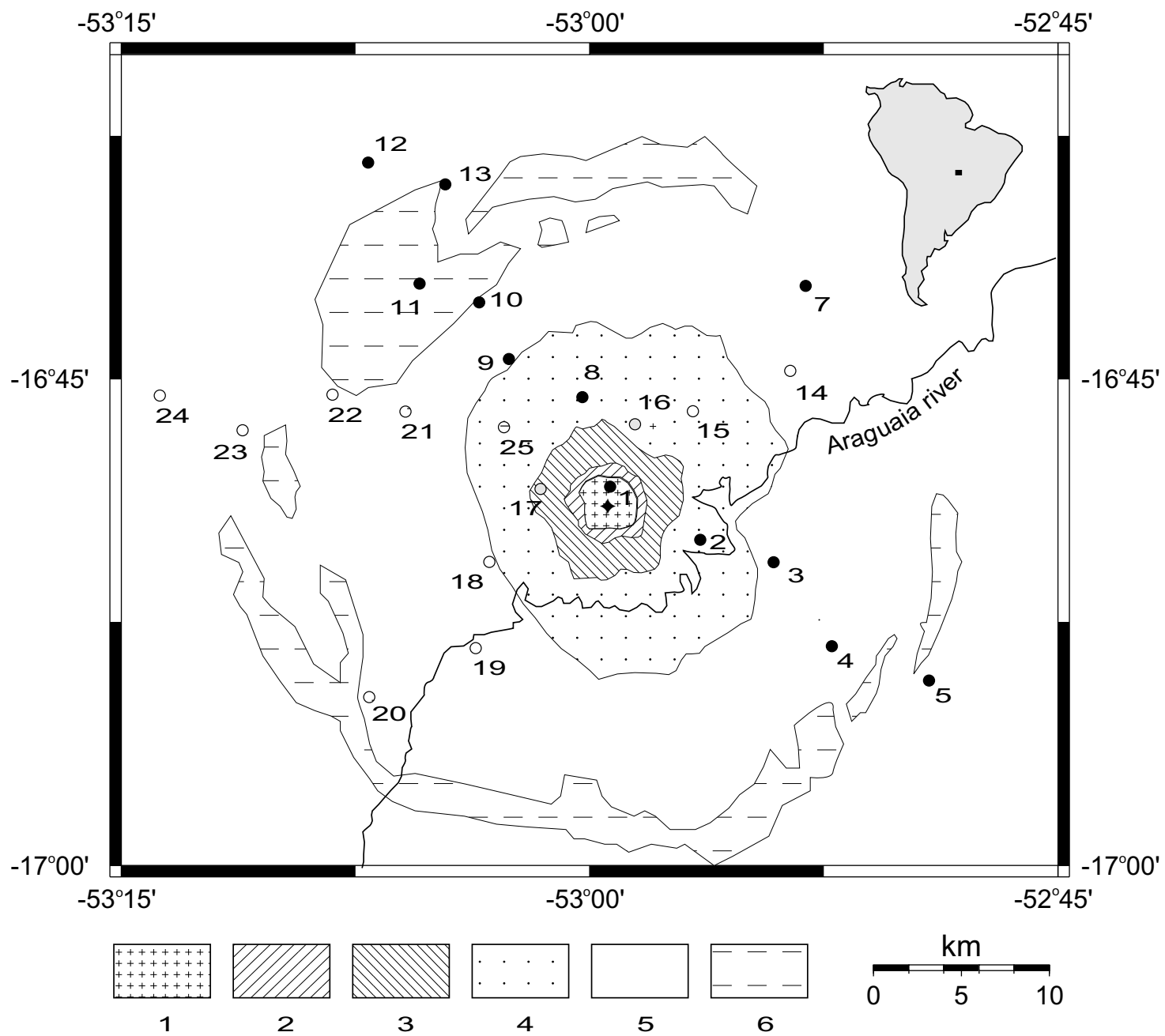

Fig. 1. Simplified geologic map of the Araguainha impact crater, showing the crystalline basement of alkali-feldspar granites (1), the impact breccia with melt matrix (2), the Palaeozoic sedimentary formations of Devonian Furnas (3) and Devonian Ponta Grossa (4), Upper Carboniferous to Lower Permian Aquidauana (5) and Permian Passa Dois (Palermo) (6) sandstones, respectively, and the location of the MT sites. Filled circles (1-13) indicate sites with full GDS data set. Sites 16 and 17 have only GDS data at $T=1 \mathrm{~s}$, whereas sites 18 to 25 have only MT data. A diamond in the centre indicates the origin of profiles. A small map of South America (top right corner) shows the location of the Araguainha structure.

\section{Site Location and Experimental Set-Up}

The MT fieldwork was carried out using two distinct systems with different signal to noise characteristics. Both systems allowed measurements of 5 MT channels ( 2 telluric and 3 magnetic components) in the period range from 0.001 to 1000 seconds. This was the actual period range of the measured data. Figure 1 shows the site distribution over the crater area. Sites 1 to 13 have been acquired with ECA CM1 1 coils, whereas sites 14 to 25 used less sensitive EMI BF-4 coils. Unfortunately, except for sites 16 and 17 at the lowest period ( $1 \mathrm{~s})$, the signal to noise ratio of the EMI coils did not allow us to investigate the very demanding part of the spectrum which extends from 0.1 to 1 second. Sites 14 to 25 contributed to the $1 \mathrm{D}$ and $2 \mathrm{D}$ modellings in our previous work, however. There is no long-period data available at site 6 , since it was not possible to achieve good electrode contact with the earth. On their map of induction arrows, Masero et al. (1997) have interpolated data from sites 18 to 20 in the dead band to yield induction arrows at $T=1 \mathrm{~s}$. This information seems error prone, so this data has been discarded.
Although the data set spans over 5 decades (see extent and quality of MT data at site 7 on Fig. 2), in the present work the extension of the band of interesting periods is intentionally limited: Toward the short period end, the limit is fixed at $0.1 \mathrm{~s}$. Using shorter periods would be meaningless, since the data would be very sensitive to irrelevant small-scale anomalies such as topographic features and drainage systems. Toward longer periods, the limit is fixed at $1 \mathrm{~s}$. at longer periods, the upper crust geomorphology becomes predominant and hides the radial symmetry of the crater. Masero et al. (1997) emphasise the restriction of the 3D character of all sounding curves to the range extending from one to a few tenths of seconds. They interpret the long-period MT data as the result of alternating resistive and conductive $2 \mathrm{D}$ blocks at depths between 15 and $30 \mathrm{~km}$, related to the Transbrazilian Lineament, or possibly with fossil hotspot plumes.

Thus, all the data used in this paper originates from time series recorded in three bands, with sampling frequencies of 4, 240 and $2400 \mathrm{~Hz}$. The series are made of 96 blocks of 1024 samples, without interruption between the blocks. 

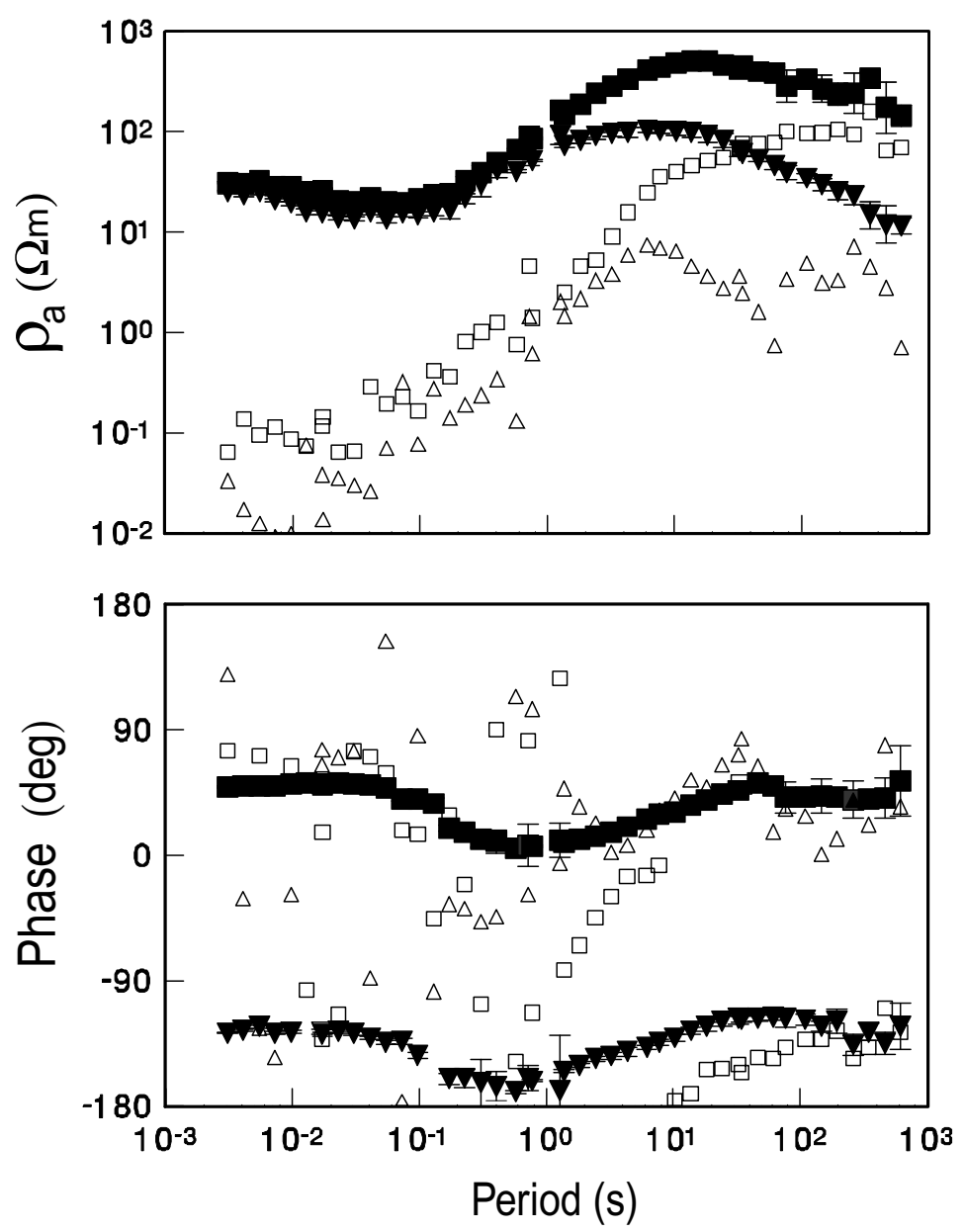

Fig. 2. Apparent resistivity and phase at site 7 vs. period (rotated $0^{\circ}$ vs. North). Full squares and triangles represent MT impedance elements $Z_{x y}$ and $Z_{y x}$, whereas empty squares and triangles represent $Z_{x x}$ and $Z_{y y}$. This figure shows the typical data extent and quality (error bars drawn for the anti-diagonal elements only).

\section{Overview of Previous MT Work on the Araguainha Dome}

To better highlight the radial character of the impact structure, the site location has been organised into 5 profiles extending from the centre of the impact crater to the periphery ((b) to (f), Fig. 3), situated at a distance of $25 \mathrm{~km}$ (Masero et al., 1994). One-dimensional modelling of the audiomagnetotelluric part of the data has been carried out at each site and the thickness of the sediments plotted against the radial distance to the crater centre. Site 17 has been arbitrarily drawn on each profile, although it belongs only to profiles (e) and (f). From this study, three geometrical parameters could be drawn:

- The uplifted basement shows up near or at the surface on a disk of 6-km radius. This value is mainly based on observations at sites 2,8 and 16 .

- The depth of the unperturbed basement is found between 1200 and $1500 \mathrm{~m}$.

- At 1-km depth, the basement displays a single ring with a $12-15-\mathrm{km}$ radius. The small site density does not allow resolution of other rings with this simple 1D modelling.
In the second paper (Masero et al., 1997) further 2D and 3D modelling of the deep structure has been carried out, but no attempt has been made to increase the resolution of the model close to the surface. On the contrary, this model was used as a known fixed structure for the upper part of the general model. However, the deep part of the 2D-3D models (depth $>15 \mathrm{~km}$ ) required the presence of a network of alternatively conductive and resistive bodies (possibly at a microscale) to explain the strong MT anisotropy and the progressively homogeneous parallel orientation of the induction arrows observed at each individual site at periods larger than $10 \mathrm{~s}$. The authors tentatively explain this anisotropy by the vicinity of the Transbrazilian Lineament.

\section{Data Modelling}

Obviously 3D modelling is still a very demanding task of computer resources. Before attempting a new modelling of MT and induction arrow data, it is important to select the best domain, both in frequency and space, so as to keep the model size within a reasonable minimum. Besides the short-period threshold set at $0.1 \mathrm{~s}$ (responding to irrelevant superficial structures), there is a long-period threshold determined by the loss of radial symmetry induced by the deep regional structure mentioned above, unrelated to the crater. 
(a)

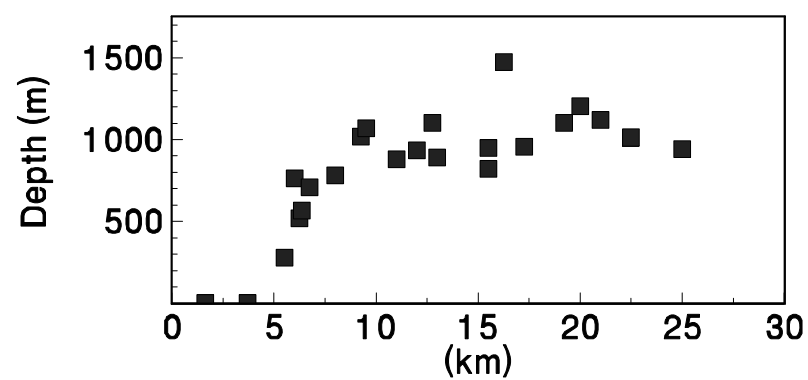

(c)

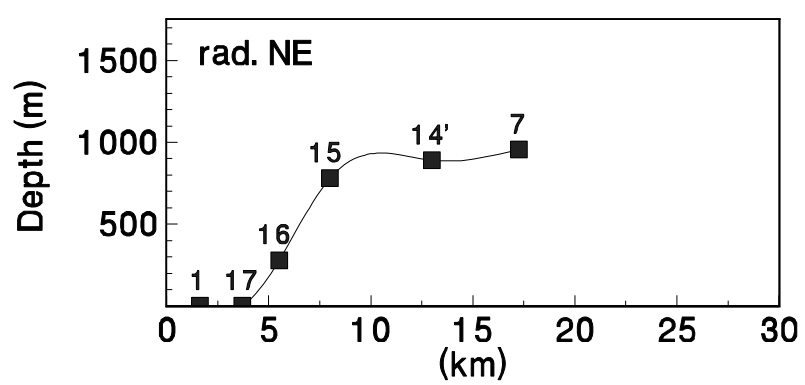

(e)

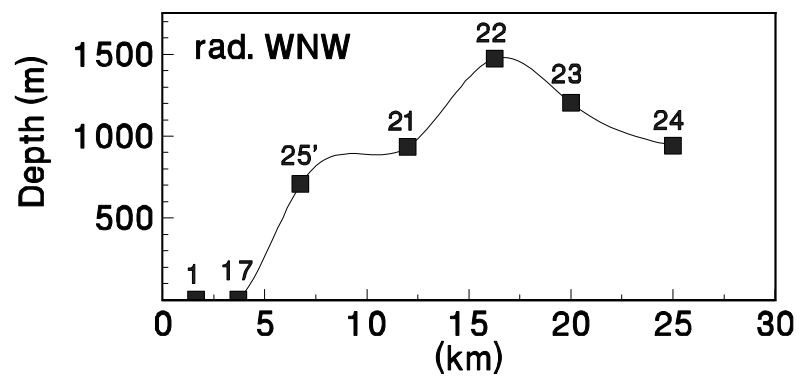

(b)

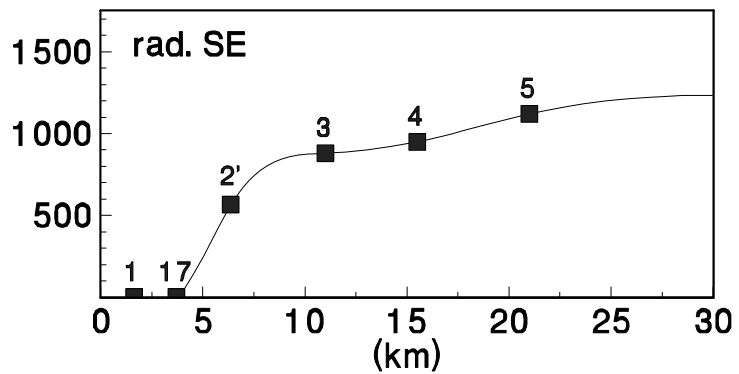

(d)

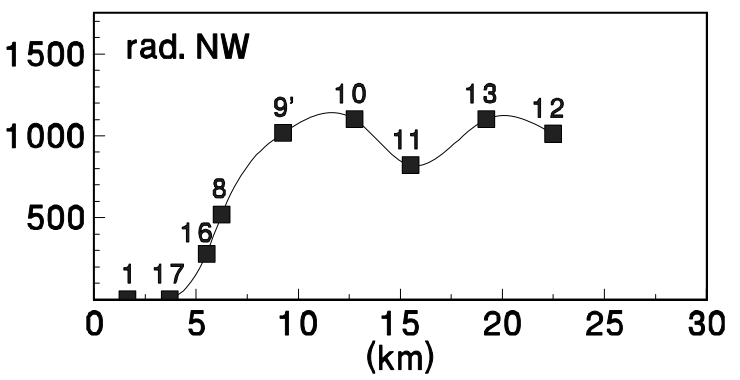

(f)

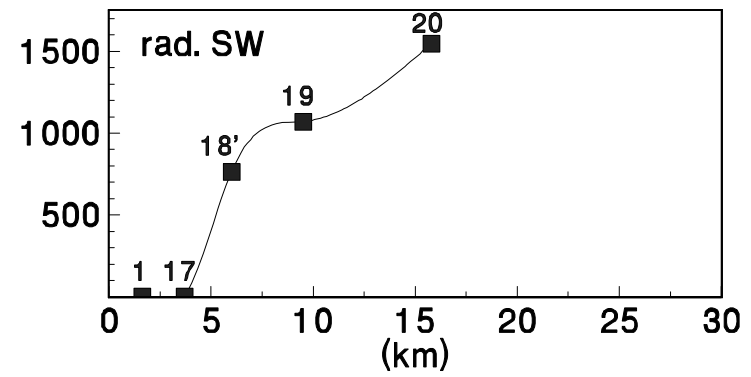

Fig. 3. Depth to the crystalline basement based on 1D models (Masero et al., 1994). (a) All depths as a function of distance to the centre (marked by a diamond on Fig. 1). (b)-(f) resulting depths for each site along different radial profiles. Note: site 17 arbitrarily drawn on each profile.

Looking at the directional variation with period of the real part of the induction arrows of two diametrically opposed sites (sites 2 and 9, Fig. 4), we see 1) that between 0.1 and $1 \mathrm{~s}$ the arrows of both sites point toward the resistive uplifted core of the crater (expected behaviour with the definition of the induction arrows used in this paper), but 2) that beyond $3 \mathrm{~s}$, they make up a complicated rotation, ending up in the SW direction. This behaviour is observed at all the sites of the survey. As 3D modelling of the full frequency spectrum is not possible with the tools at our disposal, only three periods of data have been chosen for modelling, namely 0.1 , 0.3 and 1 second. Thus, the scope of our modelling is intentionally limited to the determination of the thickness of the sediments over the impact crater as a function of the distance to the centre. Furthermore, owing to the homogeneous MT resistivity value obtained for the sediment filling and the basement (Masero et al., 1994), these parameters are kept fixed at 30 and $3000 \Omega \mathrm{m}$. Consequently, we concentrate on finding the shape of the interface between sediments and basement. An additional restriction to the geometry of the model is the radial symmetry of the geology. The shape of the interface will have a radial symmetry imposed.

The modelling scheme has been described in a recent paper (Schnegg, 1999). In a first step, the $j$ model parame- ters (layer thickness and resistivity) are considered analytical functions $F_{j}\left(\xi, \psi, p_{i}\right)$ of the generalised co-ordinates $\xi, \psi$ of the sites, and of some parameters $p_{i}, i=1, N_{j}$. The set of $i \times j$ parameters is sought so that the least square misfit between the data and the model response reaches an absolute minimum. The iterative process is carried out by a minimisation routine searching the steepest descent in the parameter space. At each iteration a model, based on the new parameters, and a regularisation mesh are automatically built. The model response is computed by a 3D forward modelling algorithm (Mackie et al., 1994), and compared to the measured data, yielding a value of the misfit, which in turn is interpreted by the minimisation routine to slightly modify the search direction in the parameter space.

Having chosen to seek a model with radial symmetry, we can reduce the problem to the determination of the best function able to represent the sediment thickness as a function of the radial distance. There are many available sets of orthogonal functions that can be used for representing a function of one variable along a finite segment, by computing limited series of these functions. The most appropriate is probably the set of Walsh functions, because their square wave nature is similar to that of the regularisation mesh of the forward modelling scheme. A graphical representation of the 

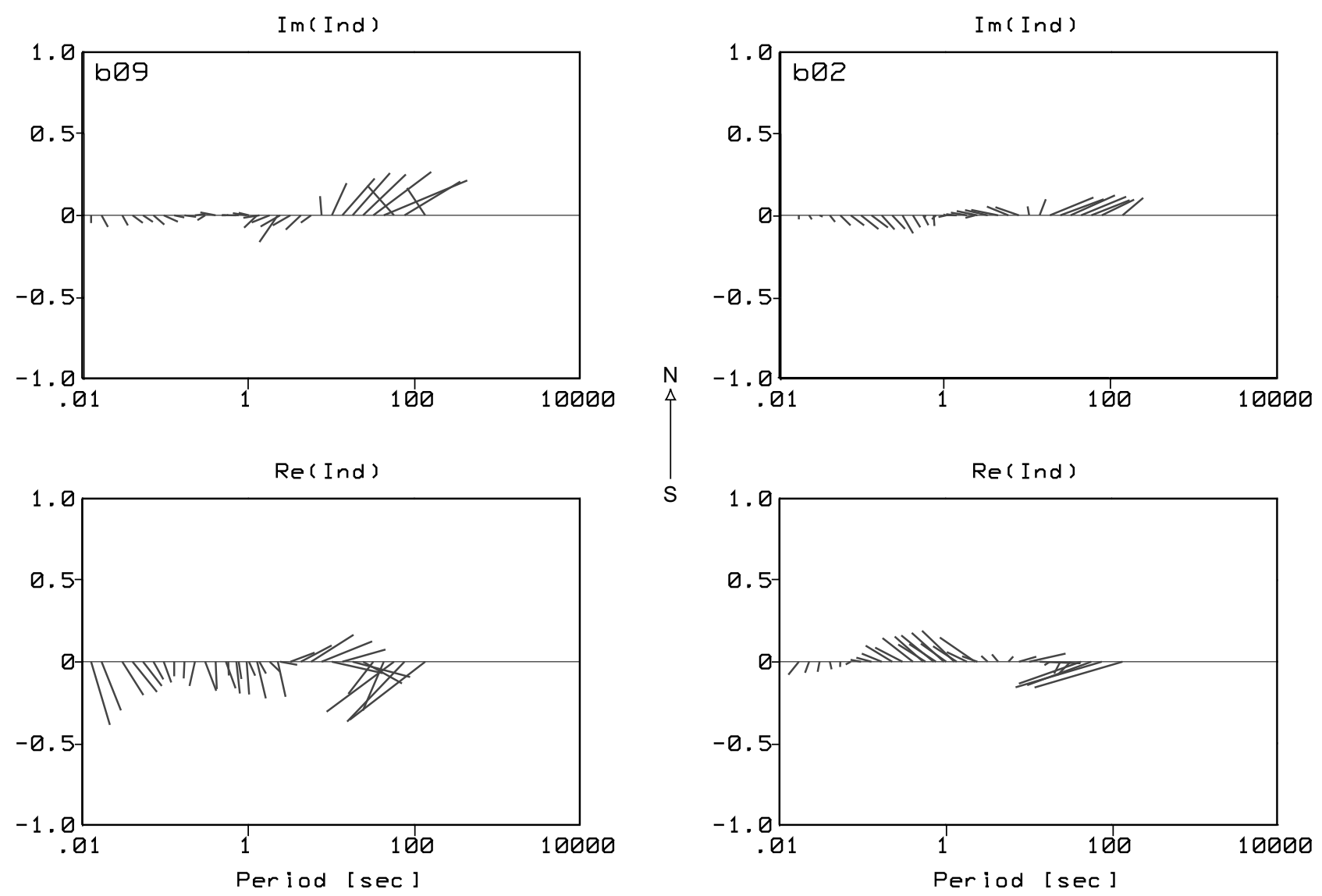

Fig. 4. Real and imaginary induction arrows at sites 2 and 9 as functions of the period. The real arrows point in the direction of increasing resistivity.

nine first functions is shown on Fig. 5. The definition (Bath, 1974) of the Walsh functions is as follows:

$$
\begin{aligned}
& w_{j}(x)=0 \quad \text { for } x<0 \text { and } \quad x>1 \\
& w_{0}(x)=1 \quad \text { for } 0 \leq x \leq 1 \\
& w_{2 j}(x)=w_{j}(2 x)+(-1)^{j} w_{j}[2(x-1 / 2)] \\
& w_{2 j+1}(x)=w_{j}(2 x)+(-1)^{j+1} w_{j}[2(x-1 / 2)] \\
& j=0,1,2, \ldots .
\end{aligned}
$$

Using this set of orthogonal functions, the radial contribution of the sediment thickness can be described as:

$$
T_{R}(r)=\sum_{i} C_{i} w_{i}(r)
$$

where $r$ is the radial distance and $C_{i}$ are the unknown parameters.

Ideally, problems of known radial symmetry should be computed with finite elements/differences schemes using model structures with a vertical axis of symmetry. Unfortunately, only schemes with rectangular space discretization are publicly available at the moment.

The size of the regularisation mesh was of $30 \times 30 \times 30$ cells. The horizontal size of the cells was $2 \mathrm{~km}$, except for the 3 outermost cells of the model, for which it was increased successively to 4,8 and $16 \mathrm{~km}$. The vertical size obeyed the following rule: the uppermost cell was $20 \mathrm{~m}$ thick, and the thickness increased by a factor of 1.2 from one layer down to the next. A check with one additional cell layer in the vertical direction showed that the total thickness of the model was large enough compared to the skin depth at the longest period, as no change of the model response was observed. Besides the fixed values of the basement and sediment resistivities, a value of $0.1 \Omega \mathrm{m}$ was assigned for the half space. The centre of the crater was set at the centre of the uppermost layer. Because the arguments of the Walsh functions vary between 0 and 1 , we normalised the radial distance with a distance of $24 \mathrm{~km}$, which is slightly beyond the topographic outer ring of the crater. The first eleven Walsh functions were used in the development, giving a horizontal resolution of $1.5 \mathrm{~km}$, that is, higher than that of the mesh along the NS and EW directions. The resistivity distribution (i.e., the resistivity of each cell) was controlled by the mathematical surface $T_{R}(r)$. Cells above and below the surface were given respectively the sediment and the basement resistivity. The misfit is defined as the distance in the parameter space between the data and the model response (Fischer et al., 1981). It was calculated using the apparent resistivities (logarithm) and phases (radians) of both anti-diagonal elements of the MT impedance, and the real and imaginary induction coefficients. The real induction coefficients have been weighted (arbitrarily) by a factor of 2 to give them more importance in the misfit calculation. The misfit is then a sum over 3 periods $(0.1,0.3$ and $1 \mathrm{~s})$ and 14 sites ( 1 to 13 , and longest period of sites 16 and 17 , see Fig. 1) of these MT and GDS coefficients. Site 6 had no 


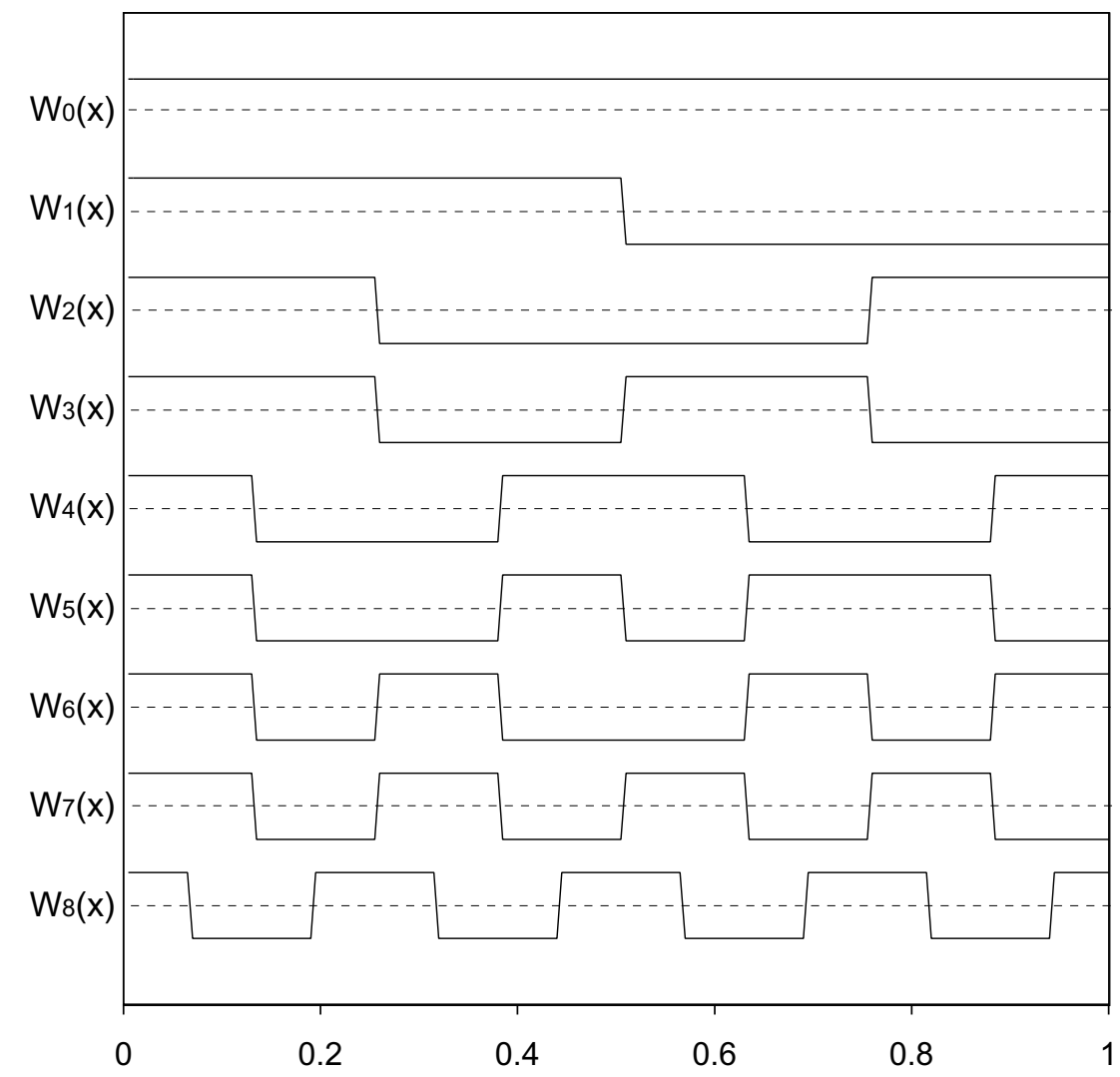

Fig. 5. The Walsh function set (first nine functions) vs. normalised radial distance. Each function varies in the $(-1 ;+1)$ interval.

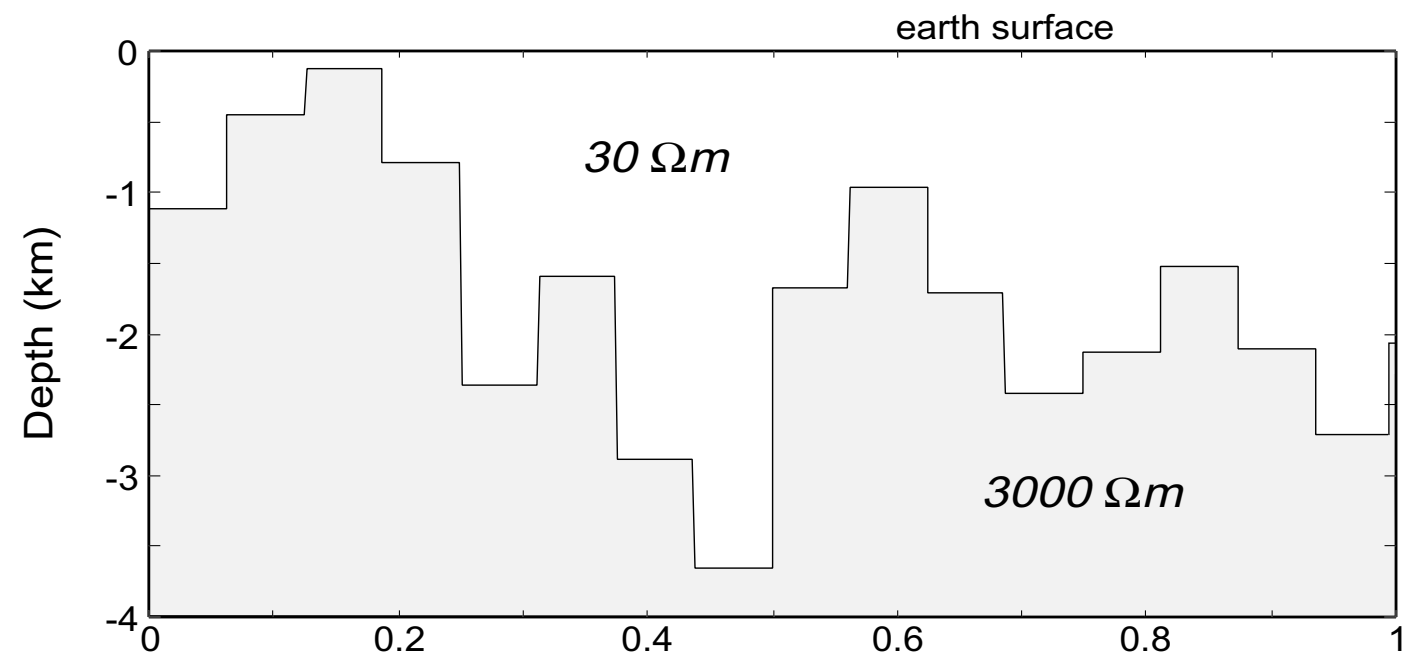

Normalised radial distance

Fig. 6. Final model showing the depth of the crater basement as a function of the normalised radial distance (1 n.r.d. corresponds to 24 km). The resistivities have been fixed to $30 \Omega \mathrm{m}$ for the sediments and $3000 \Omega \mathrm{m}$ for the basement.

usable data at all, whereas sites $18-25$ have their data in the middle of the "dead band" due to poor coil sensitivity.

The modelling scheme requires a starting model. A 1D model based on the average thickness obtained from the MT (Masero et al., 1994) was used. It corresponds to a Walsh function development with 2 non-vanishing terms
$C_{0}=C_{1}=1.43$. About 500 iterations were necessary to reach the minimum misfit of 0.054 . The final development into Walsh functions is shown on Fig. 6.

Obviously, a model with radial symmetry would be unable to account for induction arrows not pointing exactly towards the structure centre. This lack of perfect symmetry is 


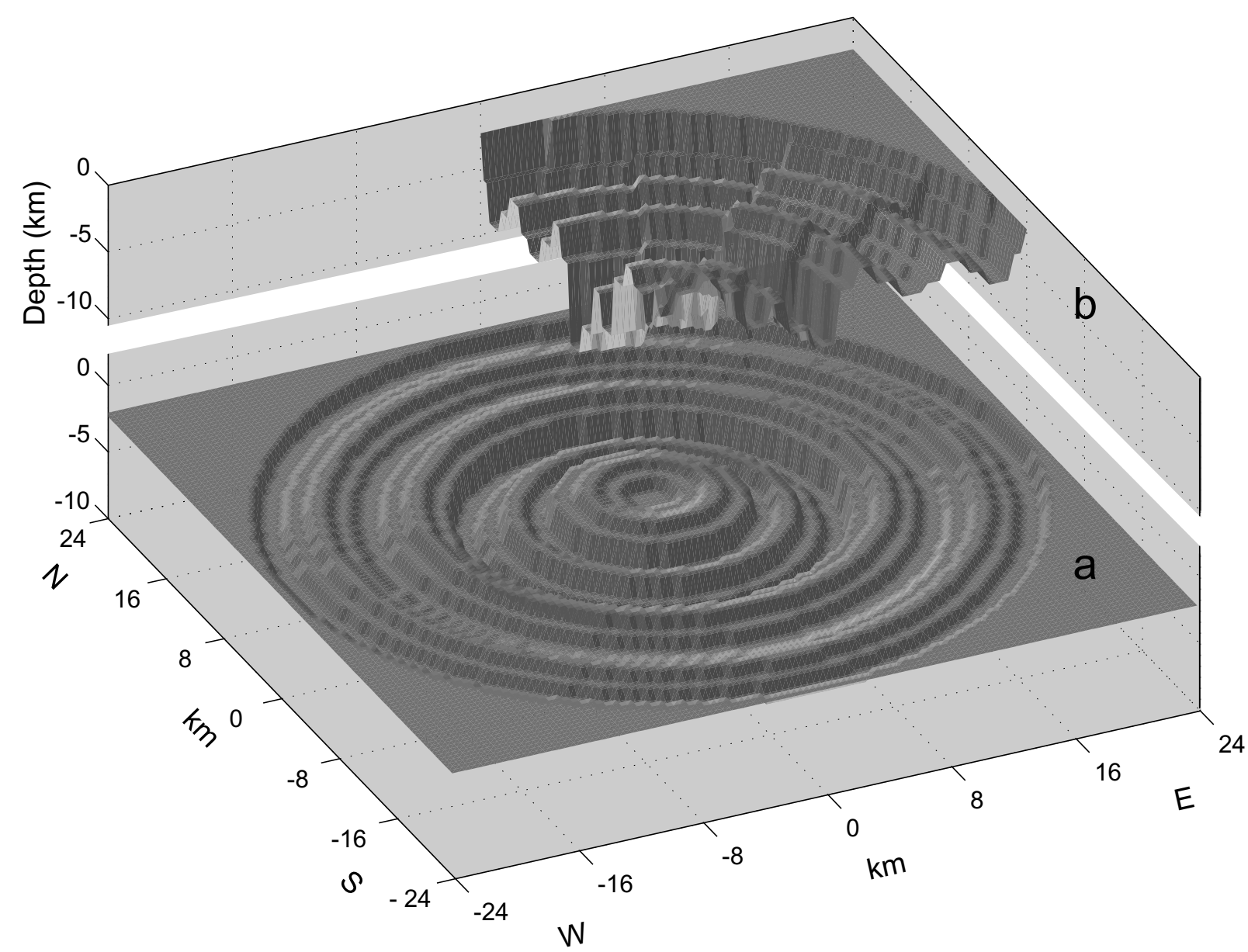

Fig. 7. Perspective view of (a) the final model showing the crater basement. (b) Partial view of the model obtained when the azimuthal variation is taken into account.

likely to occur, e.g. due to faulting and/or uneven groundwater distribution. A second-order correction to the model shape can be applied by allowing azimuthal variation of the sediment thickness. However, the number of varying parameters should not be increased, since this would be a source of instability. It is possible to decouple the radial and azimuthal functions. The sediment thickness becomes a function $T_{R}(r) \cdot T_{A}(\Phi)$, where $T_{R}(r)$ is the radial contribution of the thickness and $T_{A}(\Phi)$ the azimuthal counterpart. Here, the new function $T_{A}(\Phi)$ assumes the same explicit form as $T_{R}(r)$, with its own coefficients. This time, $T_{R}(r)$ is maintained fixed at the previously determined value, and the best development of Walsh functions is sought for $T_{A}(\Phi)$. Again, the first eleven Walsh functions were used in the development. The misfit was improved to 0.049. Figure 7 shows $3 \mathrm{D}$ views of the model without (a) and with (b) azimuthal effect. Figure 8 compares the measured and modelled real induction arrows, whereas Fig. 9 compares the apparent resistivities and phases.

In Fig. 8, reasonably good amplitude and directional fit is obtained at $T=1 \mathrm{~s}$. But the fit is not as good at lower periods, particularly for sites on the periphery. This is interpreted as the consequence of induction by superficial inhomogeneities unrelated to the ring system. Moreover, the model is unable to account for the measured imaginary induction arrows (not shown), probably due to their smaller value close to the noise limit.

The fit of the MT apparent resistivity (misfit $=0.120$ ) is not quite as good than the fit of the induction coefficients. The model phase is in better agreement with the measurement. Obviously, the apparent resistivity is affected by a small static shift, particularly at site 8 . This observation justifies the larger weight factor used for the induction parameters.

The horizontal cell size $(2 \mathrm{~km})$ may appear large compared to the vertical one $(20 \mathrm{~m})$. It is a trade-off required by the available computing capacity. Edge effects may occur locally, when the resistivity border approaches a site. However, this never occurs here, since the basement does not reach the surface of the model. Thus, little improvement could be expected from cell size reduction.

\section{Discussion}

Looking at the ring structure given by the model, we may wonder what is the reality of this complexity. Note that the site density is high enough to avoid spatial aliasing errors. Moreover, the average sediment thickness is about half the mean site separation along the profile. The overall trend 


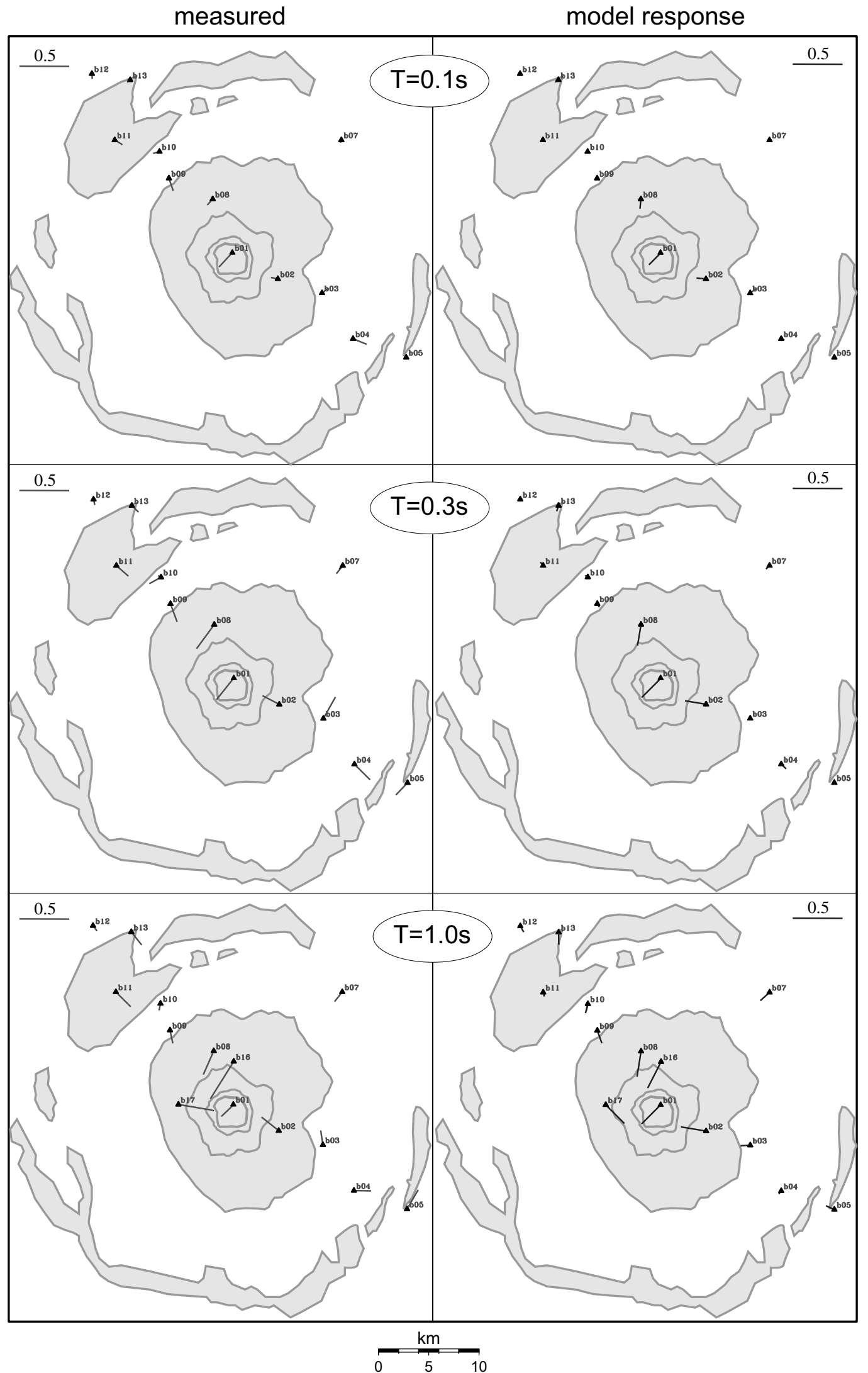

Fig. 8. Measured and modelled real induction arrows at three periods for the model including azimuthal variations, shown on a sketch of the geological map. Sites 16 and 17 have only GDS information availability at $T=1 \mathrm{~s}$. The azimuthal variations allow for non-vanishing tangent components of the arrows. 

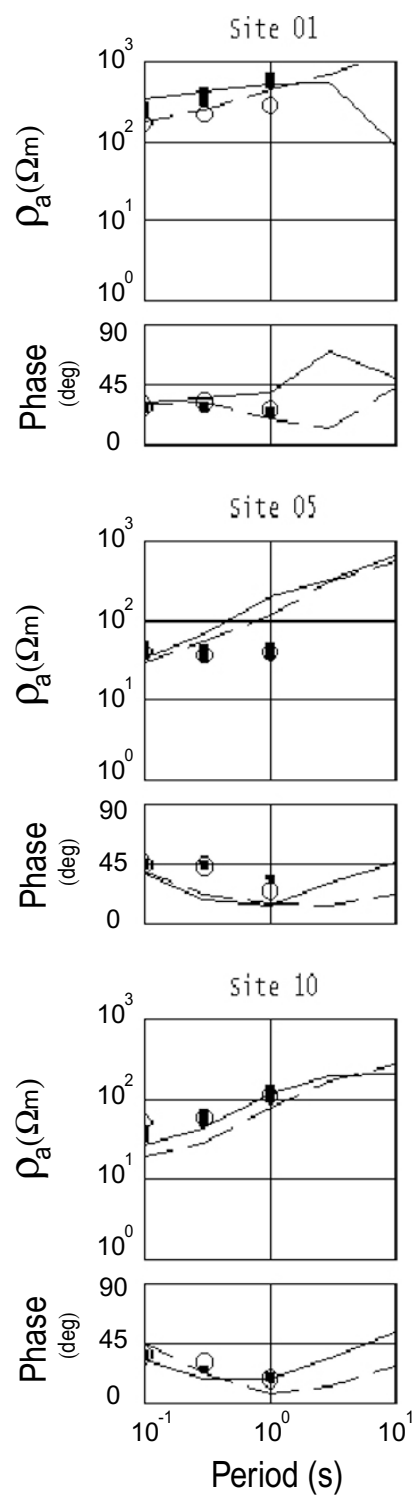

Site 02
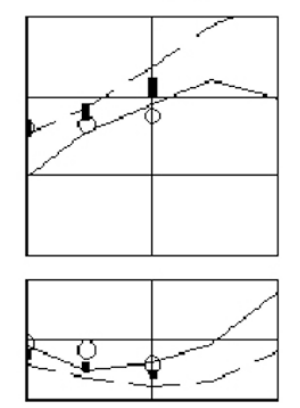

Site 07
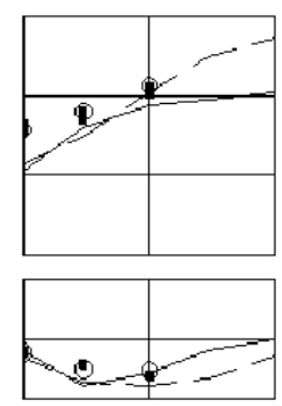

site 11
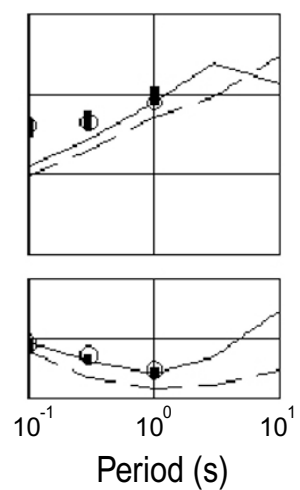

site 03
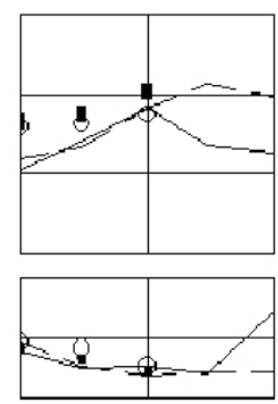

Site 08
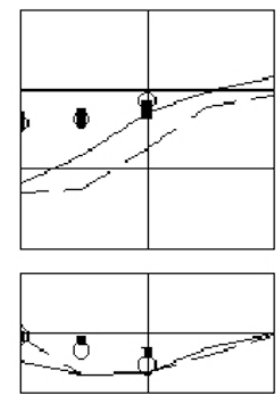

site 12
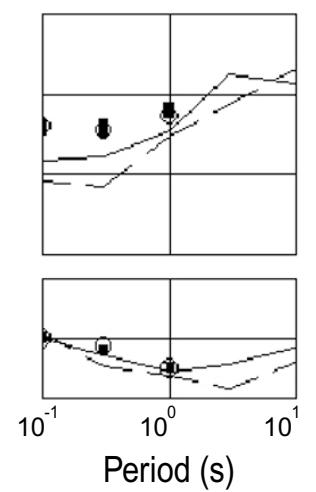

Site 04
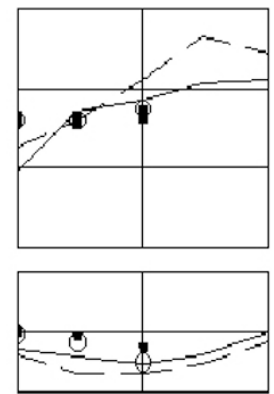

Site 09
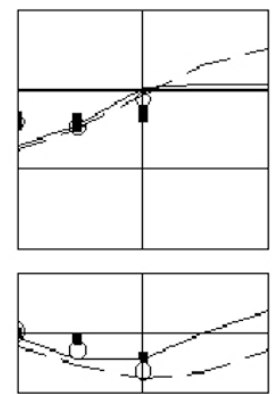

site 13
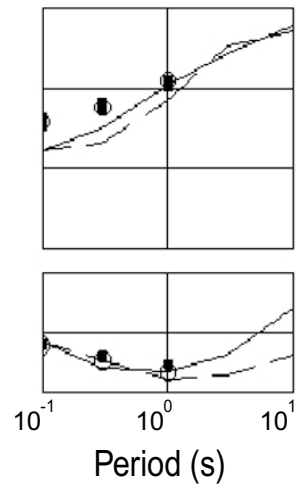

Fig. 9. Measured and modelled apparent resistivities and phases for the model including azimuthal variations. Squares and circles represent the model response corresponding to MT impedance elements $Z_{x y}$ and $Z_{y x}$, whereas broken and full lines represent measured data for these elements.

is the same as determined by the 1D MT modelling, but several new features are revealed. We believe that small details $<1 \mathrm{~km}$ along the rings are not true features and could be smoothed out from the model. The remaining features should be considered as the real topography of the crater basement.

Starting from the centre, the model displays a $0.5-1 \mathrm{~km}-$ thick, conductive body of $4 \mathrm{~km}$ diameter. This body is mainly controlled by the data at site 1 . At this site however, the induction arrow points toward the centre of the crater. By definition of the induction arrows, their direction indicates a more resistive material. This is in agreement with the known composition of the uplifted core (shocked granite and overlying breccia), but in contradiction with the conductive top of the model centre. This effect is probably a consequence of the relative large size of the mesh $(2 \times 2 \mathrm{~km})$.

At a distance of $11 \mathrm{~km}$ from the centre, the sediment thickness reaches a maximum value $>3 \mathrm{~km}$. Further away from the centre $(17 \mathrm{~km})$ a second, $2 \mathrm{~km}$-deep valley is found, surrounded by two hills culminating at -1 and $-1.5 \mathrm{~km}$. The annular structure of the Araguainha impact is easy to see on satellite images and may be the result of a propagating bounce induced by the gravity collapse of the uplifted core, a short time after the impact. Much the same effect appears on a residual gravity anomaly profile from another very large impact, the Manicouagan crater, Canada (Pilkington and Grieve, 1992). On this profile, an annular bounce and its influence on the gravity field is visible.

The best-fitting model that includes azimuthal variations of the sediment thickness (Fig. 7(b)) has here only limited significance. Obviously, the determination of azimuthal coefficients is biased by the narrow geographic distribution of the measuring sites. Most of them are aligned along a single diameter, whereas good modelling would require a homo- 
geneous distribution of sites over the whole crater area. We mention it as a feasibility study to illustrate the potential of the full modelling scheme, and not in an attempt to improve the knowledge of the local geology.

\section{Conclusion}

A new modelling effort of MT and GDS data carried out by stressing more specifically the information contained in the vertical component of the magnetic field allowed us to improve the resolution of the model. By carefully selecting the range of signal periods, it was possible to avoid geological noise encountered at shorter periods. We could also check that a model of radial symmetry could explain the direction of the observed induction arrows, as resulting from a subsurface affected by an impact, without interference from deeper structures, unrelated to the crater. The floor of the sediments within the horizontal limits of the crater is no longer seen as flat, but appears to be modulated by a damped periodic wave. This important feature remains hidden on previous models (Masero et al., 1997, Fig. 8). Obviously, the "trial and error" modelling scheme used by these authors is not ideal, since it does not make the most of the known symmetry.

The accuracy of the models of radially symmetric structures (not only impact craters, but probably also volcanoes) seems to be only limited by the number of stations deployed on the area of interest. A preliminary check of the symmetrical behaviour is necessary prior to the modelling, since the method used assumes such symmetry.

\section{References}

Bath, M., Spectral Analysis in Geophysics, 563 pp., Elsevier, 1974.

Cordani, U. G., B. B. B. Neves, R. A. Fuck, R. Porto, A. Thomaz Filho, and F. M. B. Cunha, Estudo preliminar de integração do Pré-Cambriano com os eventos tectônicos das bacias sedimentares brasileiras, Bol. Ciênc. Técn. Petról., 15, 1-70, 1984.

Crósta, A. P., J. C. Gaspar, and M. A. F. Candia, Feições de metamorfismo de impacto no Domo de Araguainha, Rev. Bras. Geociênc., 11, 139-146, 1981

Dietz, R. S. and B. M. French, Two probable astroblemes in Brazil, Nature, 244, 561-562, 1973.

Engelhardt, W. V., S. K. Matthäi, and J. Walzebuck, Araguainha impact crater, Brazil: 1. The interior part of the uplift, Meteoritics, 27, 442457, 1992.

Fischer, G., P.-A. Schnegg, M. Peguiron, and B. V. Le Quang, An analytic one-dimensional magnetotelluric inversion scheme, Geophys. J. R. astr. Soc., 67, 257-278, 1981.

Mackie, R. L., J. T. Smith, and T. R. Madden, Three-dimensional electromagnetic modeling using finite difference equations: the magnetotelluric example, Radio Sci., 923-935, 1994.

Masero, W., P.-A. Schnegg, and S. L. Fontes, A magnetotelluric investigation of the Araguainha impact structure in Mato Grosso-Goiás, central Brazil, Geophys. J. Int., 116, 377-392, 1994.

Masero, W., G. Fischer, and P.-A. Schnegg, Crustal deformation in the region of the Araguainha impact, Brazil, Phys. Earth Planet. Inter, 101, 271-289, 1997.

Pilkington, M. and R. A. F. Grieve, The geophysical signature of terrestrial impact craters, Rev. Geophys., 30, 161-181, 1992.

Schnegg, P.-A., A computing method for 3D magnetotelluric modelling directed by polynomials, Earth Planets Space, 51, 1005-1012, 1999.

Theilen-Willige, B., The Araguainha astrobleme/Central Brazil, Geolog. Rundschau, 71, 318-327, 1982.

P.-A. Schnegg (e-mail: pierre.schnegg@unine.ch) and S. L. Fontes 